\title{
Flipping Engineering by Design
}

\section{Dr. Jacqulyn Baughman, Iowa State University}

Dr. Jacqulyn Baughman Senior Lecturer, Mechanical Engineering Director of Graduate Education (DOGE), BRT Graduate Program Faculty-in-Charge, ADM Biorenewables Education Labs Iowa State University

\section{Dr. Lesya M. Hassall, Iowa State University}

Lesya M. Hassall is a program coordinator at the Online Learning Innovation Hub in Center for Excellence for Learning and Teaching, Iowa State University. Her professional responsibilities revolve around assessment and meaningful integration of learning technologies into teaching and learning, course design and development, universal design for learning and faculty professional development. Lesya received her doctoral degree in Instructional Technology from Iowa State University in 2006 and has since been involved in many teaching and learning projects, including pedagogical applications of virtual reality, mobile technologies, audience response systems and social media in higher education settings. Lesya also holds a MA degree in teaching English and German as second languages from Nizhyn State University, Ukraine.

\section{Ms. Nadia V. Jaramillo Cherrez, Iowa State University}

Nadia Jaramillo is a PhD student in Curriculum and Instructional Technology at Iowa State University. She holds a B.S in Computer Science, a B.A in teaching English, and an M.A in TESL/Applied Linguistics with specialization in Computer-assisted language learning. Nadia holds a certificate in Instructional Design. Her educational experience involves 10+ years of teaching in k12 and in higher education contexts. Currently, Nadia works as a graduate research assistant in the Online Learning Hub-Center for Excellence in Learning and Teaching at Iowa State University. Nadia works as a research assistant in the Online Learning Hub at the Center for Excellence in Learning and Teaching. Her major research projects are about the implementation and efficacy of innovative learning approaches such as flipped learning, blended/hybrid learning and team-based learning. Her research interests lie upon the intricacies amongst the design of learning environments, human-computer interaction, online learning.

\section{Dr. Mathew Hagge, Iowa State University}

Matt Hagge is a Senior Lecturer at Iowa State University. He has spent his career talking to students to figure out how students think and learn. The result of these talks has been the development of a course-wide decision framework for a thermodynamics course that allows students to solve previously unseen problems while building their expertise. This pedagogy is called Decision Based Learning, and has received tremendous student feedback and results. Students are able to solve complex problems through understanding rather than memorization and copying. Learning how to think, how to self reflect, how to take personal responsibility for learning, and the development of expert problem solving skills are all reasons why this style of teaching is life changing for many students. 


\title{
WORK IN PROGRESS Flipping Engineering by Design
}

\begin{abstract}
In a flipped mechanical engineering sophomore design course, students engaged with interactive online learning modules and follow-up graded quizzes prior to face-to-face hands-on collaborative sessions. Analysis of the student post-assessment responses demonstrated high comfort with the flipped flow of the course paired with positive online and face-to-face learning experiences. Student estimation of sufficient self-regulation for succeeding in the flipped classroom was equally positive, although analysis of their open-ended responses revealed that self-regulatory behavior was complex, developing and not as efficient as readily presented in the student responses to Likert scale questions. These findings are discussed in connection with the flipped course design and development and followed by the implications and recommendations for engineering education.
\end{abstract}

\section{Introduction}

Productive hands-on collaborative classroom sessions are integral to teaching engineering design. A mechanism for learning and in itself a learning process, engineering design is neither an entirely solo nor a totally formal affair. Engineers are expected to work in teams and be cognizant of different viewpoints and ways to accomplish a task at hand. Informal negotiations, discussions and banter among members of a design team looking for a solution to an engineering problem are part of active learning engagement ${ }^{1}$ that occurs largely during face-to-face interactions.

Much too frequently traditional engineering design classrooms are focused on imparting theoretical foundations for design analysis and mechanical design principles without allowing learners to spend uninterrupted face-to-face time on building a design product, and most importantly, collaborative reflection on and evaluation of various design and production stages. ${ }^{2}$ The fundamental idea behind flipping a classroom is that face-to-face class sessions become spaces for active engagement where students practice and problem-solve ${ }^{3,4}$ together and under the guidance of the instructor who provides immediate and meaningful feedback and assistance. ${ }^{5}$ Application exercises, routinely done as homework, are now performed in class with plentiful opportunities to make mistakes and ask for clarification. Large lectures are either eliminated or replaced with mini lectures that summarize the major points of new content to which students are exposed prior to face-to-face class sessions.

In our multi-section undergraduate introductory project-based collaborative sophomore engineering design course, student formal and informal feedback was increasingly indicative of traditional lectures as non-flexible and non-value added formats. This is congruent with the criticism of the traditional lecture as adopting an overly didactic approach to learning and focusing exclusively on providing information and very dismally- on fostering scientific discussion, analysis, and reflection. ${ }^{6,7}$ Despite its widespread adoption, the traditional lecture format has been identified as a major culprit for causing problems in STEM higher education. ${ }^{8}$ Studies show that video lectures (only slightly) outperform in-person lectures. ${ }^{9}$ Instead, flipping the emphasis towards student preparation and independent engagement with lecture materials, 
such as listening to or watching a video explanation, reading book chapters and self-assessing current understanding via a follow-up assessment makes for more productive educational activities in-class. ${ }^{10}$

The inverted Bloom's taxonomy captures the essence of the flipped format ${ }^{12}$ and its focus on the higher order stages of thinking in face-to-face class sessions that create time for effective practice of engineering design.

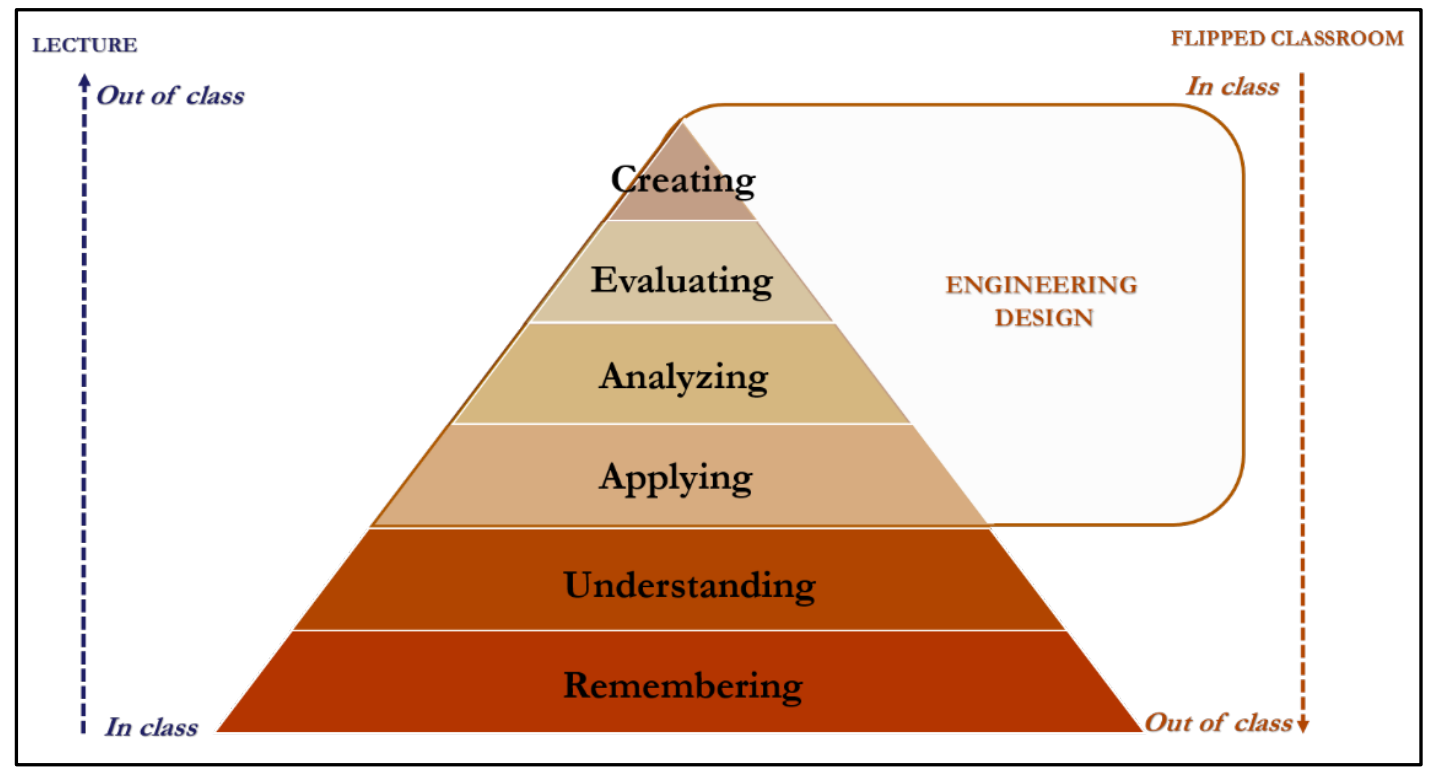

Figure 1. Flipped format for an engineering design classroom ${ }^{12}$.

\section{Advantages of a flipped classroom}

Flipped classrooms are credited with many learning benefits, ${ }^{12}$ such as more rigorous student pre-class preparation, in which independent content mastery is tied to student ability to selfmanage, self-assess and recognize connections between previous and new knowledge; respecting a student's own pace of learning; effective and creative in-class time with increased student engagement for solving real-world problems. ${ }^{13}$

Two significant problems with the flipped format were reported in the recent STEM teacher poll. ${ }^{14}$ Firstly, students may initially resist doing pre-class work independently and consequently may be unprepared for participating in active learning during class. Secondly, pre-class content if not crafted carefully and not targeting the zone of proximal development ${ }^{17}$ might be perceived as not challenging and thus not promoting learner engagement. Both are indicative of the departure from viewing students as passive consumers of knowledge and the shift towards encouraging learner motivation and engagement as well as respecting diverse ways in which students learn, engage and express what they know.

In higher education making room for active reflection and experimentation, rather than passive knowledge consumption and listening is key for creating strategic, goal-motivated and resourceful learners ${ }^{13}$. How do we convert a large enrollment undergraduate architectural engineering course to the flipped format in the ways that respect diverse ways of engagement? 
Does the flipped course flow work for future engineers? What contributes to student positive perception of the flipped format? Do students possess sufficient self-regulatory skills in order to manage their learning in the flipped classroom?

\section{Pre-Flipped Course Description and Logistics}

The questions above guided our instructional decisions as we flipped our multi-section sophomore project-based design engineering course, Mechanical Engineering (ME 270). Our course is part of the mechanical engineering department's critical design course chain, which also includes a course on introduction to engineering graphics and two senior capstone design courses (Mechanical Systems and Multidisciplinary). These critical design courses are "chained" together through prerequisites. ME 270 serves as the initial exposure to the application of engineering design tools and methodologies, which are shared across the chain.

In ME 270 students work in permanent design teams tasked with the creation of micro-economy kits (projects) resulting in a working design prototype that promotes sustainability and economic growth for developing nations. Each team's prototype is expected to meet the following requirements: it should meet a basic need in a developing region; it should improve or create a self-sustaining economic activity; it should be made from a low cost kit, using as much "local content" as possible; it could be sold and serviced by local artisans ${ }^{16}$. The course description and learning outcomes are shown in Table 1.

Table 1. Course title, description and learning outcomes

\section{ME 270 Couse description}

Introduction to engineering design and overview of mechanical engineering design

applications to thermal and mechanical systems. Introduction to current design practices used in industry. Semester-long team project focused on addressing societal needs. Past projects include designing human powered charging systems and products for developing nations.

\section{Course Learning Outcomes}

1. Demonstrate effective team work skills.

2. Create technical reports that possess appropriate structure, grammar and tone.

3. Identify the ways in which social, economic and environmental issues (the three legs of the sustainability table) impact or are impacted by the activities of the designer.

During the course, student design teams follow the Design for Six Sigma (DFSS) methodology by working through a real-life design simulation and using the toolbox called DMADVR (Define-Measure-Analyze-Design-Verify-Report) in a phase-gate exit review process shown in Table 2. The DFSS methodology allows novice engineers to experience the industry's processes for designing products that meet customer expectations ${ }^{17}$ and yield a higher level of performance. $^{18}$ 
Table 2. The DMADVR toolbox six phase-gates: Key phase-gate exit questions

\begin{tabular}{|c|c|c|c|c|c|}
\hline Define & Measure & Analyze & Design & Verify & Report \\
\hline $\begin{array}{l}\text { What are } \\
\text { the } \\
\text { customer } \\
\text { demands } \\
\text { and how } \\
\text { do they } \\
\text { define } \\
\text { your } \\
\text { design } \\
\text { and } \\
\text { product } \\
\text { goals? }\end{array}$ & $\begin{array}{l}\text { What are the } \\
\text { characteristics } \\
\text { critical to your } \\
\text { design? }\end{array}$ & $\begin{array}{l}\text { How can you } \\
\text { optimize your } \\
\text { design and } \\
\text { product } \\
\text { development } \\
\text { based on the } \\
\text { data collected } \\
\text { during the } \\
\text { Define and } \\
\text { Measure } \\
\text { stages? }\end{array}$ & $\begin{array}{l}\text { How do you } \\
\text { create a } \\
\text { product and/or } \\
\text { process that } \\
\text { will be an } \\
\text { improvement } \\
\text { from status } \\
\text { quo? }\end{array}$ & $\begin{array}{l}\text { Does the } \\
\text { product do } \\
\text { what it is } \\
\text { expected to } \\
\text { do? What } \\
\text { does it take } \\
\text { to } \\
\text { implement } \\
\text { the } \\
\text { improved } \\
\text { product } \\
\text { and/or } \\
\text { process? }\end{array}$ & $\begin{array}{l}\text { What } \\
\text { documentation } \\
\text { of the design } \\
\text { and } \\
\text { development } \\
\text { do you have in } \\
\text { place? }\end{array}$ \\
\hline
\end{tabular}

The six sections of the course typically involve a teaching team of 5 to 6 instructors (one may teach 2 sections) and 6 teaching assistants (TAs). Each section seats a maximum of 42 students. Prior to flipping, the course consisted of a 50 minute large group lecture and 6 hours of F2F team design work in a lab studio space. Five sections met 2 hours per day on Monday, Wednesday, and Friday, and one section met for 3 hours on Monday and Wednesday. The large group lecture was delivered to students from all sections of the course in a large lecture hall. DFSS tools were introduced by faculty, guest speakers from industry and teaching assistants (TAs). Individual lab instructors also covered supplemental material beyond the scope of the group lecture. These lab lectures occupied 30 minutes to one hour of the total lab time (two hour duration).

\section{Why we flipped}

The decision to flip ME 270 was motivated by several pedagogical concerns, among which were the growing course enrollment numbers that resulted in space availability conflicts, inconsistency in quality of instruction/content, accessibility and student engagement issues.

Growing enrollment and lack of space. As a large enrollment course, ME 270 required a sufficient physical space capable of accommodating all sections for a large lecture once a week. It has become increasingly challenging to coordinate the availability of large capacity physical spaces as ME 270 and other courses in the critical design course chain grew. We speculated that eliminating a weekly face-to-face lecture in ME 270 would reduce the department's need and subsequent search for available lecture halls.

Student feedback. We were fully cognizant that the elimination of one lecture a week ought to be paired with alternative access to the course's content. In their end-of the semester course evaluations, exit interviews and random discussions, our students were clear: it was not the content they objected to, it was the lengthy, non-interactive and inflexible lectures that took a toll on student motivation and engagement. In addition to student feedback, each instructor in the ME 270 teaching team documented what they learned from their own sections. Our informal analysis of the student feedback data and regular discussions within the teaching team helped to identify three key areas for course improvements, such as the following:

1) Consistency in course content and instruction in order to effectively use in-class time across sections: the ME instructors spend time on extensive lecturing in their respective 
sections often reiterating what was discussed in the large lecture; the content of such instructor monologues varied from section to section.

2) Flexible and accessible just-in-time and on-demand content: the ME 270 students complained about boring lectures and asked for flexible online engagement with new content to replace lectures and free time for actual design work. The students also asked for the possibility of working with new material on their own terms and at their own pace.

3) Engaging hands-on activities: in a series of focus group interviews, the exiting students indicated that the course lectures that were perceived as uninspiring, repetitive and nonparticipatory needed to be replaced with digestible interactive multi-media content that is tied to the skills to be practiced in the labs.

To initiate improvements, the ME 270 teaching team obtained a President's Flipped Classroom Initiative grant supported by Iowa State University's Center for Excellence in Learning and Teaching and the Provost's Office and collaborated with several senior capstone instructors and industry design engineering representatives, as well as, an instructional designer to focus on enhancing the following course aspects:

1) Student initial exposure to new knowledge through interactive online learning modules and follow-up graded quizzes meant to aid learners in understanding and assessing what they did and did not know prior to in-class sessions.

2) Engaging in-class sessions to build on student pre-class preparation and offer application exercises to practice new skills.

The ME teaching and instructional team also re-visited the course learning goals, objectives, learning activities, assessments and course logistics to align with projected student pre and inclass engagement and develop the flipped flow of the course.

\section{Flipped Course Logistics}

As a result of flipping ME 270, a weekly 50-minute lecture was eliminated. Instead, interactive online modules and assessments were created to expose students to new content prior to lab sessions. In labs, the instructors of each individual section spent the time briefly summarizing major points of the learning modules, taking student questions, initiating student discussions, conducting team-based application exercises and, more importantly, accommodating team-based design projects.

Nine learning modules were developed using Softchalk, a content authoring software tool, and integrated into a course master template residing in the institutional learning management system Blackboard (see Figure 3). The learning modules contained previously developed and new video materials representing the industry's perspective on DFSS tool usage and captured on site with a local industrial partner (each a maximum of 15 minutes in length). Text and videos were accompanied with interactive exercises, such as drag and drop, matching, sorting and quizzing and other interactive activites. The students were required to work with the learning modules at their own pace and take a graded assessment (quiz) prior to face-to-face sessions. All online materials including the Blackboard course were accessible 24/7; graded assessments closed on the day of the in-class session. In class, the students were expected to ask questions for clarification using the notes they jotted down when exploring the learning modules prior to class, participate in class discussions, and work on the team prototypes applying the appropriate DFSS 
tools introduced in the learning modules. This course flow had a significant impact on the student role in the class (see Figure 4). 
Contents $\mathbf{\nabla} \mid$ Next $>1 \mid$\begin{tabular}{lllll|l|l|l|l|l|l|l|l|l} 
& 2 & 3 & 4 & 5 & 6 & 7 & 7 & 8 & 9
\end{tabular}

\section{World Poverty Statistics}

Many developing countries suffer from extreme poverty. These are the statistics from the 2013 Human Development Report by the UN Development Program, and show the multitude of ways in which poverty impacts the quality of human life.

Drag customer requirements to match customer needs.

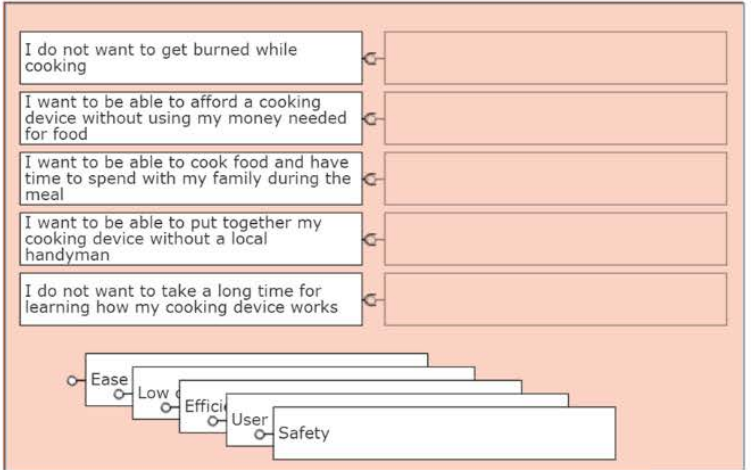

$50 \%$ ( 3 billion people) of the world's population lives on less than $\$ 2.50$ a day.

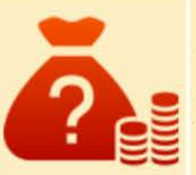

$75 \%$ of the total world income is accounted for by the richest $20 \%$ of the population.

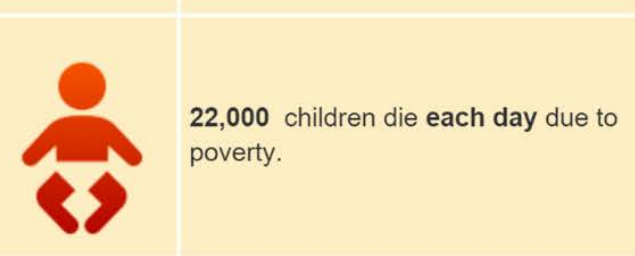

1.1 billion people in developing countries have inadequate water access.

1 in 7 (270 million) children live with no access to health services.

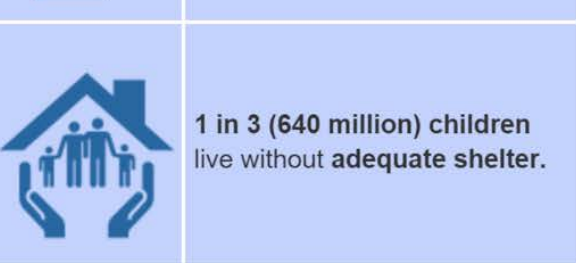

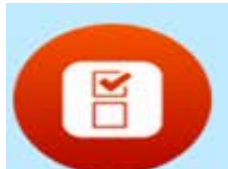

Engage with a learning module

$-\cdot-\cdots$

Mark it reviewed $-\cdots->$

Complete a quiz for points

Throughout a module, you will complete interactive exercises. You may attempt these as many times as you wish.

After you complete a module, please mark it reviewed. Once the module is marked reviewed, a quiz will be released. All questions in the quiz are scored.

Figure 3. A screenshot example of the flipped course, and its Blackboard design flow. 


\section{IN ME 270 YOU WILL ENGAGE WITH ONLINE CONTENT BEFORE YOU COME TO YOUR DESIGN LABS FOR F2F MEETINGS.}

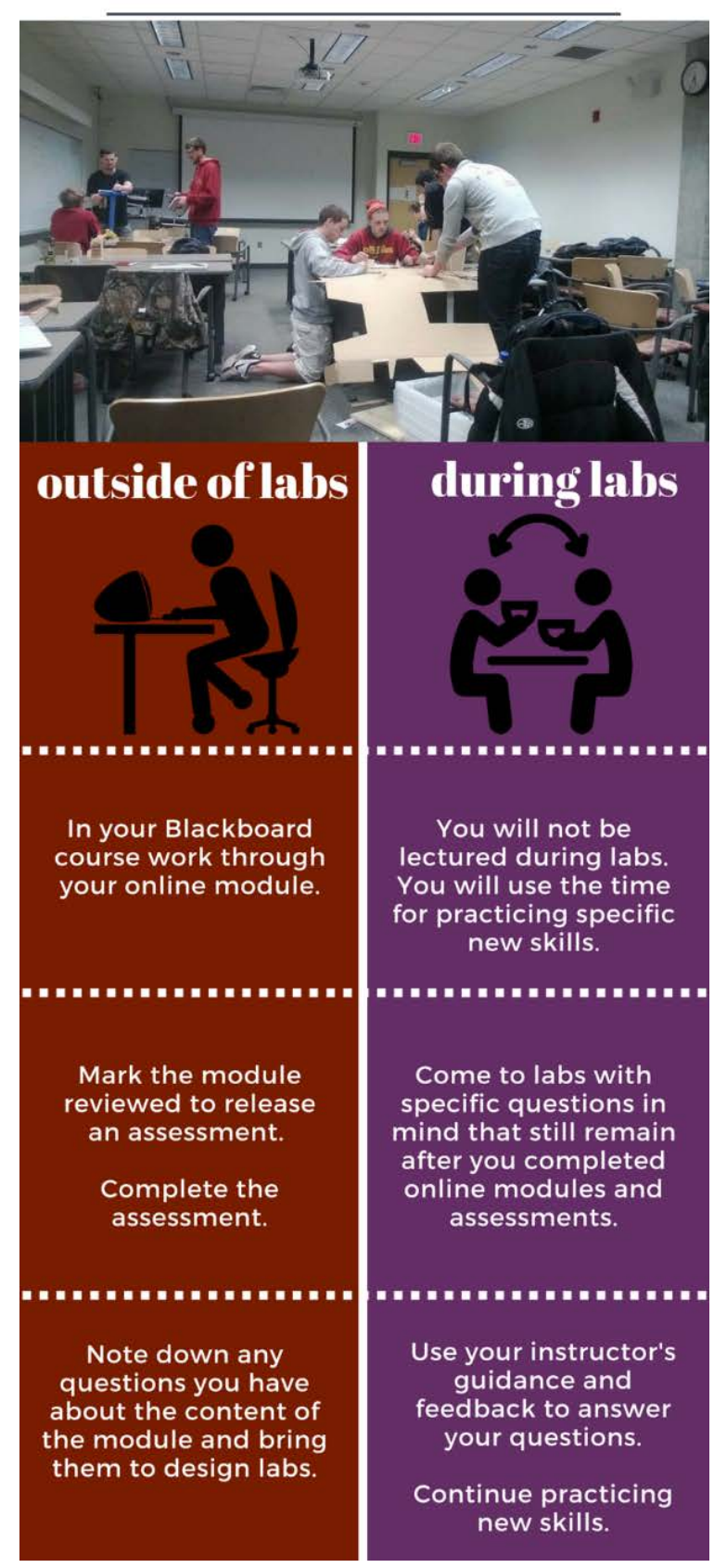

Figure 4. Student role in the flipped ME 270. 


\section{Methodology}

Upon completion of the course, the students were asked to participate in a post-assessment survey, which probed into their perception of comfort levels with the flipped flow and two course components, pre-class interactive online modules and assessments and in-class learning activities. Additionally, we were interested in determining whether students reported any selfregulatory mechanisms to monitor their progress in the flipped classroom.

Post-assessment surveys were conducted across all six sections of ME 270, with a total enrollment of 252 students. Student participation in the assessment was 54-63\%, depending on the section, totaling 158 students responding to all questions. The post-assessment survey was modelled after an existing exit surve ${ }^{20}$ which was used as a point of reference. The questions in our survey were modified to reflect the specifics of our course experiences. The survey asked 19 Likert scale questions that included items related to student perceptions of the course flow, online learning modules, in-class experiences and self-regulatory behaviors. We asked how strongly students felt about each item using a 1-5 scale where 1 was associated with strongly disagreeing, 2-disagreeing, 3-neither agreeing nor disagreeing, 4-agreeing, and 5-strongly agreeing. Additionally, the survey included two open-ended questions probing into what worked well and what could be improved in the flipped format. The survey was administered via the Blackboard course page. The outcome of interest was students' self-reported comfort with the course delivery as well as the online and face-to-face course components. Descriptive statistical analysis was performed and individual items were clustered into meaningful categories to aid in analysis. Additionally, deductive qualitative analysis was performed on the student responses to the two-open ended questions. All responses were coded and grouped into large themes to look for similarities and differences.

\section{Quantitative Results}

The student post-assessment responses are shown in Table 3. The responses to the Likert scale questions were clustered into meaningful categories, such as: 1) course flow, 2) online learning modules, 3) hands-on lab experience, and 4) study habits. Overall, the students agreed that they felt comfortable with the flipped course flow $(M=4.00)$ and that it modeled engineering design in industry $(M=3.80)$. There is an apparent agreement that the online learning modules were engaging $(M=3.44)$, supplemented with enjoyable interactive exercises $(M=3.58)$ and relevant to hands-on in-class applications $(M=3.85)$. Interestingly, the students did not report having many questions after completing the online learning modules $(M=2.85)$ in spite of rating the in-class guidance rather highly $(M=4.01)$ - the instructors and TAs in each section were very specifically charged with ensuring that all student questions about the online learning modules were addressed timely and effectively.

We could possibly explain the fact that the students had very few questions after completing their online modules $(M=2.85)$ by a dissonance between the content of the learning modules and the in-class hands on applications, something that became obvious from the student responses to the open-ended questions. Lastly, the student perceptions of their self-regulatory behaviors, or study habits, aligned well with their overall positive attitudes towards the flipped course flow and demonstrated student investment in their own learning $(M=4.00)$. 
Table 3. Flipped class post-assessment descriptive statistics.

\section{Descriptive Statistics}

\begin{tabular}{|c|c|c|c|}
\hline & & Mean & $\begin{array}{c}\text { Std. } \\
\text { Deviation }\end{array}$ \\
\hline Course flow & & & \\
\hline $\begin{array}{l}\text { 1. I was comfortable with this course's flow when I } \\
\text { learned new content prior to labs and practiced my } \\
\text { skills in labs. }\end{array}$ & 158 & 4.00 & .814 \\
\hline 2. I felt the course modeled well how engineering & 157 & 3.80 & .916 \\
\hline $\begin{array}{l}\text { design worked in industry. } \\
\text { Pre-class interactive online experiences }\end{array}$ & & & \\
\hline 3. $\begin{array}{l}\text { My online learning modules kept me interested and } \\
\text { willing to learn new content on my own prior to } \\
\text { labs. }\end{array}$ & 158 & 3.44 & 1.061 \\
\hline 4. Videos in my online learning modules illustrated \\
new content well.
\end{tabular}




\begin{tabular}{|c|c|c|c|}
\hline \begin{tabular}{|} 
13. I feel I was productive during lab times working \\
with my team.
\end{tabular} & 157 & 4.24 & .735 \\
\hline $\begin{array}{l}\text { 14. I frequently re-visited my online learning modules } \\
\text { after labs. }\end{array}$ & 158 & 2.80 & 1.166 \\
\hline $\begin{array}{l}\text { 15. I found adequate assistance from my instructors and } \\
\text { TAs after labs. }\end{array}$ & 158 & 4.01 & .794 \\
\hline Student self-regulation in the course & 157 & 4.00 & .776 \\
\hline $\begin{array}{l}\text { 16. I felt invested in my learning in this course. } \\
\text { 17. I felt responsible for my team's success in this } \\
\text { course. }\end{array}$ & 157 & 4.28 & .668 \\
\hline 18. I was managing my time well in this course. & 139 & 4.23 & .556 \\
\hline 19. My study habits worked well for this course. & 136 & 4.13 & .649 \\
\hline Valid N (listwise) & 122 & & \\
\hline
\end{tabular}

\section{Qualitative Results}

From the responses to two open-ended questions that probed into what worked well in the flipped course flow and what could be improved, the students generally agreed that they were comfortable with the flipped course flow and the way in which it respected their different ways of engaging and learning. This coincides with what was captured by the quantitative results. An elimination of the weekly 50 minute face-to-face lecture time was well received, as well as, making room for meaningful in-class discussions and uninterrupted team time for designing, building, and testing a functional prototype.

Benefits and challenges of the online learning modules. The online learning modules were reported to have solid content and accommodate flexible access which helped students to be in control of their time and engagement. The following benefits of the learning modules were frequently referenced:

1) Learning content ahead of the course schedule;

2) Reviewing learned content for missed insights;

3) Enjoying the convenience of pacing their learning;

4) Engaging with embedded exercises to better remember new content;

5) Watching videos that packed compressed hours of lecture time into digestible contextualized segments of information;

6) Self-evaluating without being punished for making a mistake.

Alongside the positive aspects, a number of student's reported a certain disconnection between the content of the learning modules and the corresponding in-class session. The reported dissonance ranged from light differences between certain processes as they were represented in the learning modules and in-class sessions to the course's larger logistical issues when the modules referenced one way of completing an assignment while the students received explicitly 
different directions in class. As a result, the students relied on the instructor and TA guidance as well as the aid of their team members for accomplishing their tasks rather than following the guidance of the learning modules. This became particularly more common towards the end of the semester, when the teams neared the completion of the functional prototype design projects and had to deal with unique engineering design problems, self-regulation issues, complex team dynamics and pressing deadlines.

This finding might help to explain why the students reported having few questions after completing the learning modules in their responses to the Likert scale item Number 6: as the course dynamics became increasingly complex toward the end of the semester, the teams found themselves in different design and production stages. The unique context of each section of the course demanded that student immediate learning needs and challenges be addressed even if at the expense of relevance between the content of the learning modules and the in-class sessions. This means that although the students expected a straightforward connection between what they learned online and what followed in the class, the actual connection between the two components of the course flow was more complex. Although the students were expected to come prepared to practice what they learned, the learning modules were not designed to cover the concepts fully; instead it was expected that in-class the students would articulate the gaps in their knowledge drawing on the learning modules. This was very different from student previous learning experiences - instead of spitting back digested information, they were asked to connect the dots on their own and then reflect and articulate on how the new content fit or did not fit with their previous knowledge. To vocalize that they in fact had questions after completing the learning modules might have put the students in an uncomfortable position. Likewise, the cookie-cutter assignment instructions were not part of the learning modules, because the intention was to challenge students and evoke their creativity, rather than dispatch the exact requirements for an excellence performance. So, bringing some uncertainty and messiness to learning was by design; the flipped format was a process to ensure that, in the end, student struggles are simply a part of learning.

Productive learning in class. The students agreed that online modules, integrated self-evaluation exercises and a follow-up graded quiz prior to in-class time helped to plan for and anticipate inclass sessions before they occurred. The in-class sessions were described as opportunities to put into practice what had been first brought to their attention in the modules, reinforce learned content through discussions with team members and the instructor and TA's guidance, and maximize time spent on collective engagement with design and production. A large number of student comments revolved around a feeling of accomplishment with which the students left the productive in-class sessions filled almost entirely with collaborative reflections, as well as, actual design and production of prototypes. The students were very vocal about appreciating minimal lecturing and maximum hands-on activities and uninterrupted design and production as unforeseen events, increased course workload, time constrains, team dynamics and other "noise" interfered with the scheduled timing for the prototyping as the semester progressed.

Self-regulation in the flipped classroom. Despite the high rankings that the Likert scale selfregulation items received, the responses to open-ended questions portrayed student selfregulatory behaviors as complex and developing throughout the course. The following selfregulatory behaviors were reported: 
1) Scanning learning modules for the big picture before focusing on more complex parts;

2) Attempting self-assessments before watching videos for answers;

3) Jotting down notes while working with the learning modules;

4) Predicting the content in videos based on the surrounding text;

5) Asking many questions of the instructor and TAs;

6) Asking many questions of the members of a team.

Commonly describing themselves as responsible, purposeful and self-directed learners who employed different learning strategies for staying on top of their course work, the students tended to see their peers as somewhat less motivated and lacking self-management skills. However, many students noted that their experiences of collaborative work tended to change their perceptions of peers for the better.

Team work brought about unique challenges, such as adjusting to each individual's schedules, becoming cognizant of the strengths of team members, establishing effective team chemistry, discovering effective labor delegation practices, reconciling different communication and work styles, coining the rules for team ethics and accountability and accepting the team member's shortcomings. Several students reported that functioning as part of a team was a learning experience on its own that prompted them to reflect on their own contribution to the prototype design and development and compare their share against that of the other team members. In an attempt to solve team-conflict and self-regulate, the students embraced soft skills: for some sharing equal amount of work was effective; for others, establishing individual member roles and accountability was critical. Having learned to trust, the students tended to more frequently discuss and review the content of the learning modules with their team members. Having struggled with the projects as part of a team, made many students realize they had become better learners capable of performing and overcoming difficulties. Having become cognizant of the strengths and contributions of the others, the students were more accepting of the individual differences.

\section{Discussion and implications}

Our student experiences in the sophomore mechanical engineering design course were positive. Students were comfortable with the flipped flow of the course, in which they engaged with interactive online modules and follow-up assessments prior to class, and practiced and reflected on new skills in class. As the course developed and the students found themselves emerged in learning, team interactions, design, production and the pressing dynamics of the course deadlines, the flipped format accommodated student diverse needs and created room for resolving learning and logistical issues. The flipped format became a way to pro-actively react to what was occurring immediately in the classroom and intended by design - to help students learn that mechanical design can be messy and fuzzy and that clear cut instructions do not necessarily lead to successful design products. The flipped classroom was structured to equip the students with both, the discipline's conceptual knowledge, tools and processes as well as challenge and develop their subject matter interest. Additionally, the students were learning to learn, becoming more cognizant of and developing their own self-regulatory mechanisms in order to stay on top of their course- and team work.

The larger implications for teaching mechanical engineering design in higher education settings call for embracing the concept of the flipped format to allow novice engineers learn new content 
at their own pace using the technological capabilities to their fullest and designing interactive multi-media and engaging instructional materials that encourage further inquiry. The major challenge is to ensure that first exposure to new content is at the understanding and remembering (lower-order) thinking levels, and then to continue motivating learners. The in-class component of the flipped classroom should be designed in ways that activates learned content by allowing for application, analysis, synthesis and creation, the higher-order thinking skills. Prior to class content learned independently should be brought into face-to-face interactions in ways that highlight critical processes, concepts and relationships and provide opportunities for students act upon and express what they know. Although the in-class components should build on the preclass components, what happens in face-to-face interactions might need certain improvisations from instructors who would adapt their flipped classrooms to the pressing needs of their students. Thus, it is critical to emphasize how the flipped format functions and how it changes the role of students from passive consumers to motivated and self-directed inquirers who are not only charged with learning the discipline, but also with developing metacognitive coping skills and strategies.

Importantly, the flipped format is not a mere reduction of contact time spent with students as the case of eliminating a weekly lecture hour might suggest. Flipping means shifting away from the instructor-focused classroom, from the environment which revolves around the authority figure of the instructor and towards the student-centered space, in which learners take responsibility and prepare to participate actively and together with others in the learning experiences whose ultimate purpose is to shape reflective, innovative and collaborative engineers.

\section{References}

1. Dym, C. L., Agogino, A. M., Eris, O., Frey, D. D., \& Leifer, L. J. (2005). Engineering design thinking, teaching, and learning. Journal of Engineering Education, 94(1), 103-120.

2. Kiefer, S. and Kuchnicki, S. (2013). Project-based learning: Teaching engineering design not tinkering. $120^{\text {th }}$ ASEE Annual Conference \& Exposition. Atlanta, June 23-26, 2013.

3. Yadav, A., Subedi, D., Lundeberg, M. A., \& Bunting, C. F. (2011). Problem-based Learning: Influence on students' learning in an electrical engineering course. Journal of Engineering Education, 100(2), 253-280.

4. Tucker, B. (2012). The flipped classroom. Education Next, 12(1), 82-83.

5. A.W. Chickering and Z.F. Gamson, "Seven principles for good practice in undergraduate education.” AAHE Bulletin, 39: 3-7, 1987.

6. Baillie, C., \& Fitzgerald, G. (2010). Motivation and attribution in engineering students. European Journal of Engineering Education, 25(2), 145-155.

7. National Academy of Engineering (NAE). (2005). Educating the Engineer of 2020: Adapting engineering education to the new century. Washington, DC: The National Academies Press.

8. Sheppard, S. D., Pellegrino, J. W., \& Olds, B. M. (2008). On becoming a 21st century engineer. Journal of Engineering Education, 97(3), 231e234.

9. P.A. Cohen, B.J. Ebeling, and J.A. Kulik. A meta-analysis of outcome studies of visual-based instruction. Educational Technology Research and Development, 29(1):26-36, 1981.

10. Wankat, P. C., Felder, R. M., Smith, K. A., \& Oreovicz, F. S. (2002). The scholarship of teaching and learning in engineering. Disciplinary styles in the scholarship of teaching and learning: Exploring common ground, 217237.

11. Herreid, C. F., \& Schiller, N. A. (2013). Case studies and the flipped classroom. Journal of College Science Teaching, 42(5), 62-66.

12. Honeycutt, B. and Garrett, J. (2013). The flipped approach to a learner-centered class. A Magna Publications White Paper. Available: http://www.magnapubs.com/white-papers/the-flipped-approach-to-a-learner-centeredclass-3098-1.html. Last accessed Jan. 29, 2016. 
13. Fulton, K. (2012). Upside down and inside out: Flip your classroom to improve student learning. Learning \& Leading with Technology, 39(8), 12-17.

14. Mangan, Katherine. "Inside the flipped classroom." The Chronicle of Higher Education, October 4 (2013): B18.

15. Herreid, C. F., \& Schiller, N. A. (2013). Case studies and the flipped classroom. Journal of College Science Teaching, 42(5), 62-66.

16. Lehmann, M., Christensen, P., Du, X., \& Thrane, M. (2008). Problem-oriented and project-based learning (POPBL) as an innovative learning strategy for sustainable development in engineering education.

17. Vygotsky, L. (1978). Mind and Society. Cambridge, MA: Harvard University Press.

18. Mader, D.M., 2002. Design for six sigma. Quality Progress July, 82-86.

19. Treichler, D., Carmichael, R., Kusmanoff, A., Lewis, J., \& Berthiez, G. (2002). Design for Six Sigma: 15 lessons learned. Quality Progress, 35(1), 33.

20. Fautch, Jessica M. "The flipped classroom for teaching organic chemistry in small classes: is it effective." Chemistry Education Research and Practice16, no. 1 (2015): 179-186. 